\title{
Estudo sobre os riscos da profissão de estivador do Porto do Mucuripe em Fortaleza
}

\author{
Occupational risks among dock workers \\ in the Port of Mucuripe, Fortaleza, Brazil
}

\author{
Francisco Fábio Gadelha Cavalcante 1 \\ Anna Ca roline Nobre Gomes 1 \\ Francisco Roberto de Araújo Nogueira 1 \\ João Luís Melo de Farias 1 \\ João Maurício Ribei ro Pinhei ro 1 \\ Emanuel Veras de Albuquerque 1 \\ Antônio Leomar Pei xo to Farias 1 \\ Gabriel Barroso Cabral 1 \\ Francisco Alexand re Cunha Magalhães 1 \\ Márcia Gomide 1
}

\footnotetext{
1 Departamen to de Sa ú de Comunitária, Faculd ade de Medicina, Un iversid ade Federal do Ceará.

Rua Prof. Costa Mendes, 1608 , 5 andar, DSC,

Rodolfo Teófilo, 60031-970, Fortaleza CE.

fabiogcavalcante@aol.com
}

Abstract The stevedores of the Port of Mucuripe are workers without employm ent bond with the Company Dock of Ceará. They act in the deck and the stowage of the ships, making the embarkment, the landing and the organization of containers. In this environment of constant exposition to risks, occupational physician is basic in the organization of plans of prevention of accidents, education of the workers and monitorization of the risks. The objective of this article is to characterize and to know the stevedore's job, to correl a te the port environment and its productive process with the factors of risk and the damages associates, as well as standing out the importance of the Occupational Medicine for the control of such risks. The fiel dwork was developed in the months of January and February of 2003, with the application of 60 questionnaires to the steved o res. The analysis of the data evidence that the main inherent problems of health this stevedore's job are, among others, the osteo-articulate (lumbar disc hernia and consumings in the joint of the knee) and metabolic disturbances (diabetes and arterial hipertension). These if not only must to the work, but also and, with great influence, to the context of life of these professionals.

Key words Stevedore, Occupational medicine, Occupational illnesses
Resumo Os estivadores do Porto do Mucuripe são trabalhadores sem vínculo em pregatício com a Companhia Docas do Ceará. Atuam no convés e no porão dos navios, fazendo o embarque, o desem barque e a organização doscontêineres. Neste ambiente de constante exposição a riscos, o médico do tra balho é fundamental na organização de planos de prevenção de acidentes, de educação dos trabalhadores e de monitorização dos riscos. O objetivo do artigo é caracterizar e conhecer o estivador, correl a cionar o ambien te po rtuário e o seu processo produtivo com os fatores de risco e os agravos associados, bem como ressaltar a importância da medicina do trabalho para o controle de tais riscos. O trabalho de campo foi desenvolvido nos meses de janeiro e de feverei ro de 2003, com a aplicação de 60 questionários aos estivadores. A análise dos dados evidencia que os principais problemas de saúde ineren tes à profissão de estivador são, en tre outros, os distúrbios osteoarticulares (hérnia de disco e desgastes na articulação do joelho) e metabólicos (diabetes e hipertensão arterial). Es tes se devem não só ao trabalho, mas também e, com grande influência, ao contexto de vida destes profissionais.

Palavras-chave Estivador, Medicina do trabalho, Doenças ocupacionais 


\section{Introdução}

Segundo Merino (1996), até hoje não existe uma norma mundial que regulamenteo transporte e manu seio de cargas. Exis tem convênios que fixam o peso limite (va rian dode 20 até 100 $\mathrm{kg}$ ). A Organização In ternacional do Trabalho - OIT (1988) recomenda que em atividades $n$ a s quais o peso exceda a $55 \mathrm{~kg}$ devem ser tomadas medidas o mais rapidamente para reduzi-lo. A mai oria dos países pos sui uma legislação/recomendação sobre o manuseio e movimentação de cargas. Sem dúvida, os trabalhadores não estão to talmente pro tegidos, já que as leis não são adequadas ou cumpridas. Assim, nos dias de hoje, ainda é comum en contrar países onde o trabalho de manuseio de cargas se mantém com as características utilizadas há muitas décadas. É possível encontrar locais onde são transportadas manualmente cargas que superam os $100 \mathrm{~kg}$, como no caso dos estivadore s.

Con forme Na jar \& Morrone (1985), grande parte dos acidentes de trabalho poderia ser evitada se existisse uma legislação mais adequada e funcional. Assim, verifica-se que os problemas lombares apresentados por trabalhadores que manuseiam cargas pesadas no Brasil representam aproximadamente $70 \%$ dos casos.

Em outros países, também existem probl emas. De acordo com a litera tu ra especializada, $o$ incorreto manu seio e a movimentação manual de cargas são a causa mais freqüente de acidentes de trabalho individual. Um exemplo é que nos Est ados Unidos, $50 \%$ das incapacid ades tem porais são motivadas por qu edas no manus eio de cargas. Isto constitui um grande risco para a coluna vertebral, especialmente a região lombar.

O Brasil é um país que investe pouco em prevenção de aciden tes de trabalho. Con forme Silva et al. (1996), a maioria dos acidentes ocorre pelas más condições de trabalho, pois o próprio corpo do trabalhador é sua ferram enta de trabalho. Do total arrecad ado pela Previdência Social, apenas $1 \%$ é destinado a atividades de prevenção, enquanto o restante é destinado a pagamentos de benefícios acidentários, de acordo com Ba rreiros (1990). Essa situação poderia ser evitada se foss emcumpridas as medidas da NR-29 (Norma Regulamentadora de Segurança e Saúde no Trabalho Portuário) que tem o obj etivo de regular a proteção obri gatória contra acidentes e doenças profissionais, facilitar os primeiros-socorros a acidentados e alcançar as melh ores condições possíveis de seg u rança e s a ú de aos trabalhadores portuários.
O Porto Organizado de Fortaleza (Porto do Mucuripe) sof reu uma grande mudança após a m odernização dos portos. A lei 8.630, conhecida como a Lei dos Portos, trouxe uma profunda reformulação nos concei tos postos em prática na vida portuária brasileira, notadamen te no que diz respei to à ex p l oração das instalações portuárias, à prestação dos serviços, às relações capital-trabalho no trabalho, à administração portuária e à participação do Estado na ativi$\mathrm{d}$ ade do porto.

O trabalho de estiva deixou de ser predom inantemente braçal e se tornou de ori entação na or ganização de contêineres nos conveses e nos porões de navios. Assim, atualmente, aos conhecidos problemas inerentes à profissão, como doenças de pele, muscular e osteoarticular, somam-se os distúrbios por esforços repeti tivos.

De acordo com o OGMO/FOR (Órgão de Gestão de Mão-de-Obra do Trabalho Portuário do Porto Organizado de Fortaleza) no período de janei ro de 1999 a janei ro de 2003, no Porto do Mucuripe houve um total de 116 aciden tes de trabalho no ambi en te portuário, sendo que 61 dos casos $(52,59 \%)$ envo lveram a categoria de estivador. Os demais acidentes se referem aos portuários, aos conferentes, aos arrumadores e aos funcionários. Os tipos de lesão mais prevalentes entre os Trabalhadores Portuários Avulsos (TPAs) foram as con tusões $(36,21 \%)$ e os ferimentos $(24,14 \%)$, observando-se ainda entorses, escoriações, fraturas, tra umas, luxações e queim aduras.

Neste contex to, observa-se o descaso e a pouca rel evância que é dada à profissão, tan to no que diz respeito a trabalhos e a pesquisas publicadas quan to à atenção dispensada pela socied ade e pelas autori d ades responsáveis.

O obj etivo de s te arti go é, portan to, ca racterizar e conhecer o estivador, correlacionar o ambiente portuá rio e o trabalho com os fatore s de ri s co e os agravos associados, bem como re ssaltar a importância da medicina do trabalho na organização de planos de prevenção de acidentes, na educação dos trabalhadores e na monitorização dos riscos.

\section{Ma terial e métodos}

No Porto do Mucuripe há 213 estivadores, distribuídos entre estivador de porão, de peação, guincheiro e sinalei ro. O estivador tem como a tividade a movimentação de merc adorias nos conveses ou nos porões das embarcações prin- 
cipais ou auxiliares, incluindo o transbordo, a arrumação, a peação, a desapeação, bem como o carregamento e a descarga das mesmas, s endo realizadas com equipamen tos de bordo e os rech egos a bordo.

Dentre os 213 estivadores, aproximadamen te $62 \%$ têm entre 30 e 45 anos. Apenas um tem idade inferior a 25 anos e quinze têm idade superi or a 55 anos.

Quanto ao nível de escolaridade, 59,15\% dos estivadores concluíram o ensino fundamental II (até a 8a série). Existindo dois trabalhadores analfabetos, como também, dois com ensino superior. Os demais estão distribuídos em alfabetizado, ensino fundamental I (até a 4a s é rie) e ensino médio (até o 3o ano).

Este estudo é fruto de uma pesquisa realizada no período entre janeiro e feverei ro de 2003 por meio de umque stioná rio estrutu rado com 38 questões mistas, aplicado a 60 estivadores do Porto do Mucuripe em Fortaleza. O questionário foi dividido em três partes. $\mathrm{Na}$ parte inicial constam oito perguntas gerais, visan do caracterizar o perfil básico dos trabalhadores. Na segunda parte, constam perguntas sobre as condições de trabalho dos profissionais da estiva. Na última parte, procurou-se iden tificar agravos específicos à saúde do entrevistado, tais como os relaci on ados à pele, ao músculo, às articulações, à coluna e ao uso de drogas.

Esses dados foram colhidos antes do início dos tu rnos de trabalho, no galpão de chamada, com três grupos de dois e um grupo de três entrevistadores. Foram feitas 24 entrevistas às $6 \mathrm{~h} 30 \mathrm{~min} ; 21$, às $11 \mathrm{~h} 30 \mathrm{~min}$; e 15 , às $17 \mathrm{~h} 30 \mathrm{~min}$, podendo o en trevistado trabalhar dois turnos por dia, desde que sejam intercalados por seis horas de fol ga e que haja vaga. A escolha do entrevistado foi aleatória e a en trevista, com perguntas diretas, dependia do consentimen to do mesmo.

Como elemento adicional da coleta de dados, o grupo proc u rou informações com o OGMO/ FOR, com a CIPA (Comissão In terna de Prevenção de Acidentes), com o SESSTP (Serviço Especializado em Seg u rança e Sa ú de do Trabalhador Portuário), com a Companhia Docas do Ceará, com o Sindica to dos Estivadores e dos Trabalhadores em Estiva de Minérios do Estado do Ceará e com o médico do OGMO/FOR.

Para ilustrar o trabalho, foram feitas fotografias dos profissionais em atividade. Posteriormente, as respostas dos questionários foram digitadas e analisadas com o auxílio do softwa re Ep i - In fo 2002.

\section{Resultados}

\section{As pectos gerais do estiva dor}

Todos os estivadores do Porto do Mucuri pe são homens, com a idade variando entre $24 \mathrm{e}$ 67 anos, média de 41 anos $\pm 9,3$. Dos 60 en trevistados: $3,3 \%$ são analfabetos; $10 \%$, somente alfabetizados; $25 \%$, com ensino fundamental 1 ; $40 \%$, com ensino fundamental $2 ; 20 \%$, com nível médio; e 1,7\%, com nível superi or.

O tem po de trabalho va riou de 2 a 48 anos, com média de 14 anos $\pm 8,4$. A maioria dos estivadores, $58,3 \%$, tem o hábito de trabalhar doi s tu rnos por dia.

Com relação a diabetes, $80 \%$ afirmaram não ter; $6,7 \%$ disseram ter; $13,3 \%$ não sabiam se eram diabéticos. No que diz respeito à hipertensão arterial, $81,7 \%$ afirmaram que não têm pressão alta; $10 \%$ afirmaram que sim; e 8,4\% não souberam re s pon der.

\section{Condições de trabalho}

Quando perguntados se dispunham de alguma assistência de saúde, a resposta predom inante foi não (78,3\%). Apesar de o OGMO afirmar que exige acompanhamen to médico periódico (anual), 10\% afirmaram não exigir. Com relação à periodicidade, dos que afirmaram que a empresa exige o acompanhamento, $75,9 \%$ disseram que vão anualmente; $14,81 \%$ dis seram que vão semestralmente e $9,25 \%$ afirmaram que vão quan do qu erem ou não foram no ano de 2002.

Todos afirm a ram que usam capacete, botas e luvas como Equipamentos de Pro teção Individual (EPI). Ao serem questionados se sua profissão traria algum agravo a sua saúde, 66,7\% confirmaram. Além disso, 11,7\% preocupamse com os ri s cos que sua profissão acarretam ao ambiente.

\section{Agravos à saúde}

\section{- Pele}

Apesar de estarem expostos ao sol, 81,7\% afirmaram não usar qualquer proteção contra o mesmo. Quando perguntados sobre a existência de problemas de pele no último mês, $20 \%$ referi ram o probl ema neste perí odo (Figura 1). Dos que apresentaram probl emas de pele, 50\% fizeram algo para solucionar o problema, sendo que des tes metade solu ci onouo problema. 
Figura 1

Percen tual dos diferentes ti pos de lesões de pele referidos pelos estivadores do Porto do Mucuri pe no último mês.

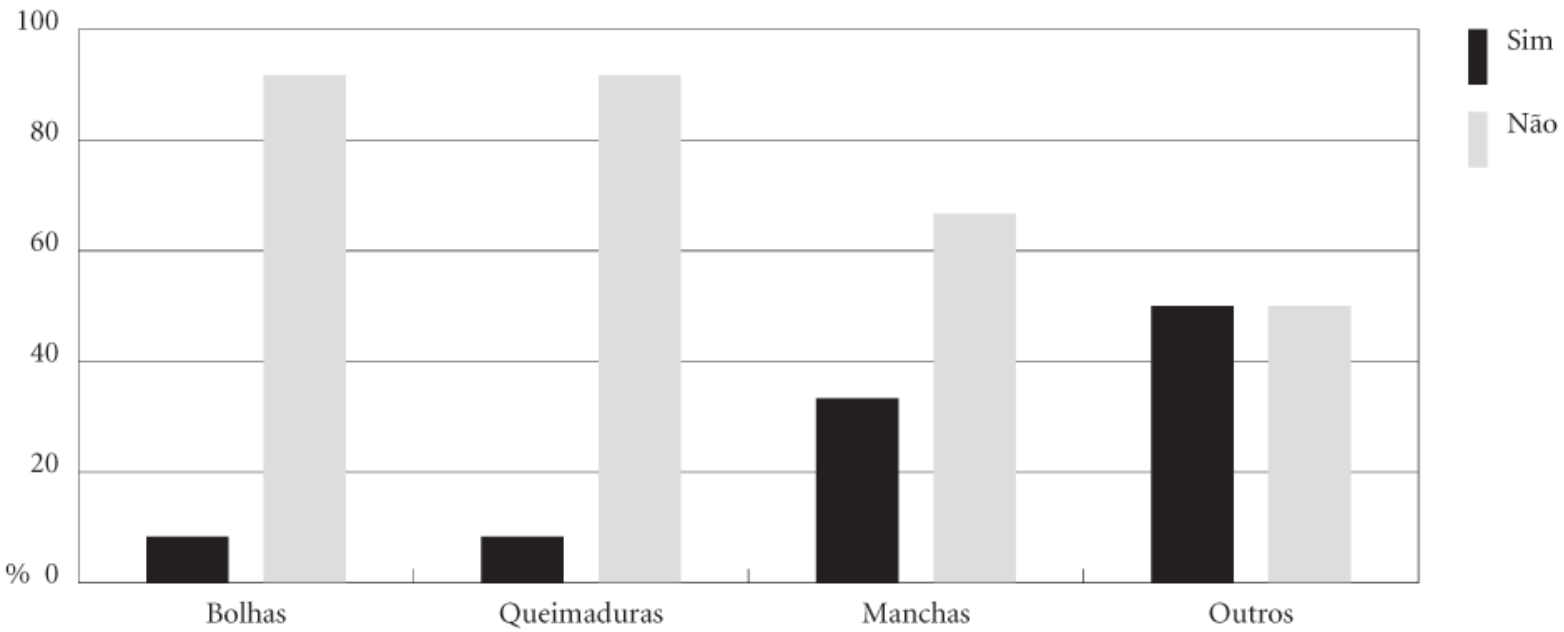

Fortaleza-CE, janei ro e fevereiro/2003.

\section{- Músculos}

Ao serem questionados se sentiram dor muscular que os impediram de trabalhar nos úl timos três meses, $23,3 \%$ re s pon deram positivamente. A distri buição percen tual das regiões do corpo relatadas está descrita na figura 2.

\section{- Coluna vertebral}

Após o questionamento sobre a existência de dores na coluna vertebral nos últimos três meses, $45 \%$ confirmaram. A tabela 1 mostra a duração de tempo destas dores. Dos que apresentaram tais dores, $51,9 \%$ procura ram soluc i onar o probl ema, dosquais, a penas $42,9 \%$ solucionaram-no.

\section{- Articulações}

Quantoàs articulações, 28,3\% dos en trevistados afirmaram terem sentido dores em algum momento nos últimos três meses, as regiões citadas estão na figura 3. Dos que apresentaram probl emas articulares, 59,7\% procuraram solucionar o(s) problema(s), dos quais a penas $45,5 \%$ obtiveram êxito.

\section{Comportam en to social}

\section{- Con sumo de álcool}

Quarenta e nove en trevistados $(81,7 \%)$ disseram que bebem, cuja freqüência está demon strada na figura 4 .

\section{- Con sumo de en torpecentes}

Apenas duas pessoas (3,3\%) relataram fazer uso de substâncias para ficar acord ado durante o trabalho, uma pessoa utilizava "arrebite"; a outra, maconha. Além disso, o uso de d rogas ilícitas foi relatado por $16,7 \%$ (10 pessoas) dos en trevistados.

\section{Discussão}

Foi observado que todos os entrevistados que relataram ser diabéticos e/ou hipertensos são etilistas, o que permite confirmar a literatura médica, a qual afirma que o uso de bebidas alcoólicas influencia no aparecimen to de tais doenças. Conforme Waskiewicz \& Zaborski (1998), 11\% dos estivadores estu dados tinham hipertensão arterial, corroborando com a prevalência de $10 \%$ do nosso estudo. Segundo Waskiewicz (1997), 32,2\% dos estivadores pos- 


\section{Figura 2}

Distri buição percentual das regiões do corpo com dores musculares referidas pelos estivadores do Porto do Mucuripe, que os impediram de trabalhar nos últimos três meses.

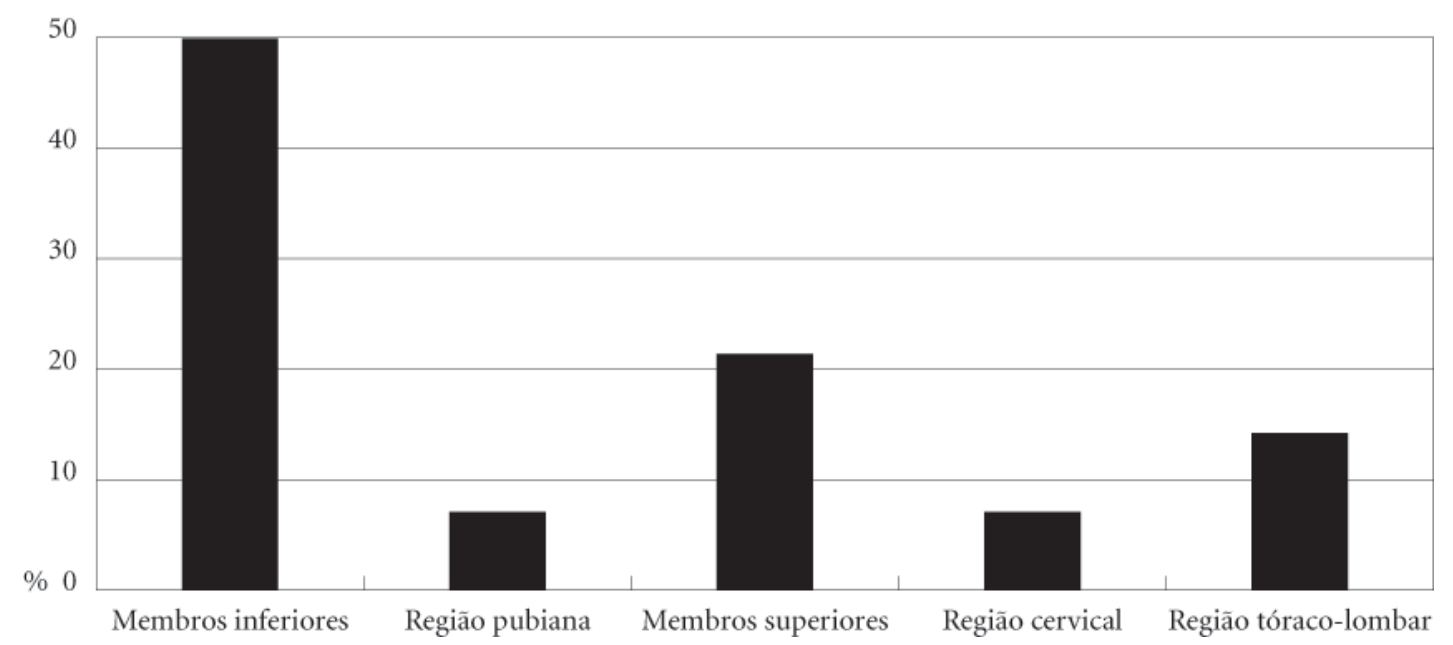

Fortaleza-CE, janei ro e fevereiro/2003.

\section{Tabela 1}

Du ração de tempo do(s) episódio(s) de dores na coluna nos últimos três meses apresentadas por 27 e s tivadores entrevist ados do Porto doMucuripe.

\begin{tabular}{lccc}
\hline Duração (em meses) & $\begin{array}{c}\text { Número de } \\
\text { en trevistados }\end{array}$ & $\begin{array}{c}\text { Percentual } \\
\text { absoluto }\end{array}$ & $\begin{array}{c}\text { Percentual } \\
\text { acumulado }\end{array}$ \\
\hline 1 & 8 & $29,6 \%$ & $29,6 \%$ \\
2 & 1 & $3,7 \%$ & $33,3 \%$ \\
5 & 1 & $3,7 \%$ & $37,0 \%$ \\
Acima de 12 & 17 & $63,0 \%$ & $100,0 \%$ \\
\hline
\end{tabular}

(Fortaleza-CE, ja n eiro e fevereiro/2003)

Obs.: Não houve valores intermediários

suíam sinais ao el etrocardiograma de hipertrofia do ven trículo esqu erdo.

Apesar de o OGMO forn ecer assistência de saúde, foi constatado existirem estivadores que a desconhecem ou julgam não terem o direito de usufruí-la. Supõe-se, então, h aver um déficit na comunicação en tre o OGMO e os profissionais da estiva.

De acordo com o órgão ges tor, o acompanham en to médico anual é obrigatóri o, porém alguns trabalhadores não rela ta ram tal exigência, o que sugeriria uma falta de controle, de compromisso e, até mesmo, de interesse por parte das autori d ades respon sáveis.
Todos os en trevi s t ados afirm a ram utilizar os E PIs fornecidos pelo OGMO, mas foi relatado por membros da CIPAdu ra n tea col eta de dados a existência de negligência tanto de uma parcela dos trabalhadores, que os utilizam apenas na presença de fiscais, bem como por parte de alguns destes, que parecem desprezar o uso dos equipamentos. Diante des te fato é importante ressaltar que os equipamen tos de pro teção individual podem ser úteis e necessários em algumas circunstâncias, porém, não devem ser a única nem a mais importan temedida de proteção.

No que diz respeito aos riscos (sob um ponto de vista amplo deste termo) que a profissão 


\section{Figura 3}

Distri buição percentual das regiões do corpo com dor articular referida pelos estivadores do Porto doMu cu ripe nos últimos três meses.

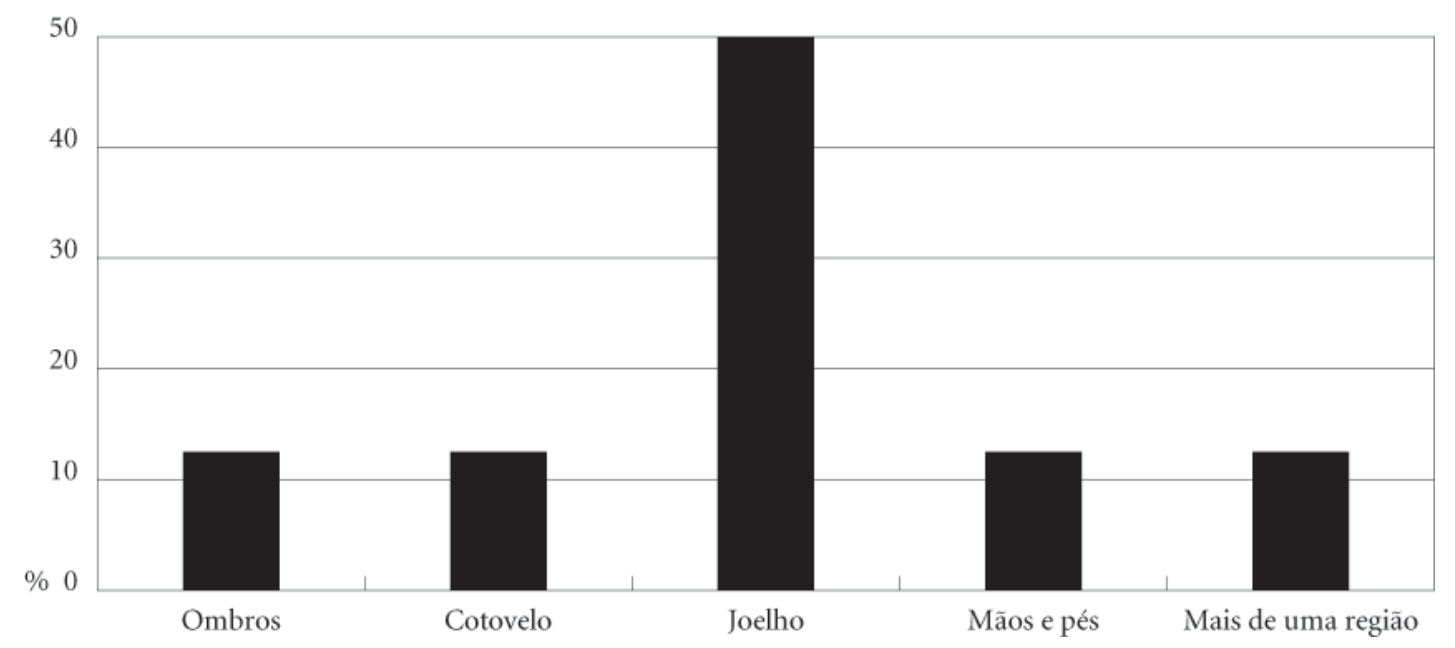

Fortaleza-CE, janei ro e fevereiro/2003.

\section{Figura 4}

Distribuição percen tual da freqüência de estilismo referida pelos estivadores do Porto do Mucuripe.

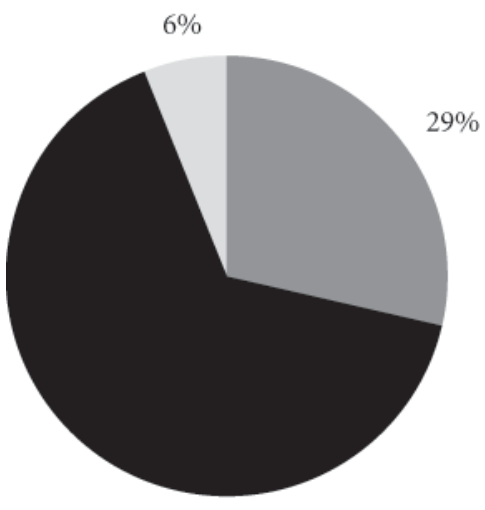

$65 \%$

Raramente ou eventos sociais

Fins de semana

Mais de 2 vezes por semana

Fortaleza-CE, jan eiro e fevereiro/2003. 
traria aos estivadores, foi constatado que um percen tual significativo tem consciência de algum tipo de prejuízo acarret ado pelo exercício profissional. Entretanto, no que se refere a agravos ao meio ambi en te, ob servou-se pouca relevância, sob a ótica geral dos estivadores, haja vista a reduzida quantidade percentual que a fi $\mathrm{r}$ ma ram haver algum prejuízo. Deve-se salientar que estes ach ados não têm relação com o nível de escolarid ade dos trabalhadores portuários.

Comprovou-se que eles relatam ter agravos à saúde com relação à pele, músculos, articulações e coluna, sen do este último o mais prevalen te ( $45 \%$ dos en trevistados). Uma explicação peculiar para estes agravos é a dificuldade de manobrar o contêiner, pois quando este está suspenso pelo guincho e sof re desvios de direção e/ou sentido pelo ven to, o estivador deve empurrá-lo para colocá-lo na posição correta. Desse modo, seus músculos e articulações ficam sobrec a rregados, já que um contêin ercheio pode pesar até 30 toneladas. Estes resultados corroboram com estu dos anteriores. Hil debrandt (1995) afirma que a co luna é o local mais atingi do do sistema locomotor quan do se realizam a tivi d ades que requ erem a movimentação e manu seio de cargas, jun to com uma postura inadequada. Segundo Mendes (1997), este trabalho repetitivo de sobrecarga, ao longo de meses ou anos, constitui um fator de ris co para doençasmusculares e articulares. Observou-se, também, que estes agravos são em sua maioria probl emas crônicos (du ração maior que um ano).

Para a discussão da relação dos agravos de saúde com o tempo de estiva, subdividiu-se esta va riá vel em categorias, as quais são: 2 a 6 anos = grupo $1 ; 7$ a $12=$ grupo $2 ; 13$ a $18=$ grupo $3 ; 19$ a $24=$ gru po $4 ; 25$ a $30=$ gru po $5 ; 31$ a $36=$ grupo $6 ; 37$ a $42=$ grupo $7 ; 43$ acima $=$ grupo 8 .

$\mathrm{Na}$ análise das tabelas foi observado que os estivadores com tem po de serviço do grupo 2 apresentaram uma maior prevalência de lesão de pele, de dor articular e de dor na co luna vertebral. Mas não foi verific cada uma relação estatisticamen te significante en tre estes agravos $(\mathrm{p} \cong$ $0,08, p=0,62$ e $p=0,66$, respectivamen te) com o tempo de serviço. Apenas na dor muscular há significância estatística com as categorias de anos de trabalho estabel ecidas, sen do o $\mathrm{p}<0,05$. (Ta bela 2)

Deve-se considerar a importância médica e epidemiológica de stes valores, pois estas doenças ocupacionais são mui to freqü en tes no ambien te portuário. Algumas podem ser tratáveis através de terapêuticas adequadas, seja dínico, cirúrgi co, fisioterápico ou outro, como con tusões, en torses, distensões, ferimen tos lácerocontusos, hipertensão arterial sistêmica de repouso ou a que se agrava com esforço e diabetes mell $i$ tus des compensada. Outras podem ser irrecuperá veis por serem irreversíveis e/ou incuráveis, abrangen do lesão/doença limitante para todas as funções da atividade portuária, bem como para quaisqu er funções possíveis de serem exercidas fora do porto. Is to é devido à con seqüência da natureza e ex tensão da lesão/ doença, e/ou por não satisfa zercrité rios de el egibilid ade para re a bilitação, por exemplo idade, escolaridade, concomitância de outras doenças.

Do obs ervado, a penas duas pessoas afirm aram fazer uso de drogas estimulantes. Tal fato não corre s pon de à realidade de acordo com in-

\section{Tabela 2}

Relação entre o tem po de serviço e a presença de dor muscular referida nos últimos três meses entre os e s tivadores do Porto doMucuripe.

\begin{tabular}{lccc}
\hline $\begin{array}{l}\text { Grupos de tem po } \\
\text { de serviço }\end{array}$ & $\begin{array}{c}\text { Apresentaram } \\
\text { dor muscular }\end{array}$ & $\begin{array}{c}\text { Não apresentaram } \\
\text { dor muscular }\end{array}$ & Total \\
\hline 1 & 1 & 5 & 6 \\
2 & 12 & 20 & 32 \\
3 & 0 & 6 & 6 \\
4 & 1 & 9 & 10 \\
5 & 0 & 2 & 3 \\
6 & 0 & 3 & - \\
7 & - & - & 1 \\
8 & 0 & 1 &
\end{tabular}


formações fornecidas por membros da CIPA. Logo, percebe-se o receio por parte dos entrevistadbs de admitir o uso de drogas ilícitas.

O médico do trabalho do OGMO atua na avaliação de doenças e/ou lesões que acom etem o trabalhador portuário avulso, relacionadas ou não ao trabalho, mas sintomáticas. Estas podem com prom eter o exercício da função ou serem agravadas pela atividade laboral.

De acordo com estu dos de senvolvi dos pelo médico do trabalho do OGMO (Programa de Con trole Médico de Saúde Ocupacional/PCMSO e Probl emas Relacion ados à In a ptidão Laboral no Porto de Fortaleza), o papel da medicina do trabalho sobre essa área ocupacional é capacitar e motivar os trabalhadores para ações responsáveis e eficientes no trabalho, bem como para atitudes de pro teção à saúde do indivíduo e do meio ambi en te, torn a n do-se uma aliada às operações portuárias de qualidade, produtividade e com peti tividade. O profissional médico poderá atuar sob cinco aspectos:

\section{Ações primárias de saúde}

- Educação em saúde, através de palestras, cartazes ou folhetos inform a tivos e motivadores, tratando de assuntos como: prevenção de aciden tes de trabalho; educação em primeiros socorros; prevenção em doenças crônico - degenerativas (diabetes, HAS, coronariopatias e etc.); DST/AIDS; higi ene pessoal e lazer.

- Imunizações para todos os trabalhadores que exercem suas ativid ades no Porto de Fort aleza vêm a ser uma ação de suma importância, sobretudo em um ambiente on de há entrada de navios de outras bandeiras, os quais seriam possíveis disseminadores de doenças.

\section{Ações secundárias de saúde}

- Realização de exames médicos obriga tórios quando da admissão, do retorno ao trabalho, da troca de função e da demissão, além, obvi amente, dos exames periódicos. Todos esses cuid ados são rel evantes para evitar possíveis ações judiciais da parte do trabalhador con tra a empresa, além de garantir sua qualidade de vida, e, porcon seguinte, sua produtivid ade.

- Elaboração de perfis profissiográficos, com a descrição da atividade, os serviços realizados durante a jorn ada de trabalho, as máquinas ou os equipamentos utilizados, as condições ambientais, a intensidade e o tempo de exposição aos agentes nocivos e o padrão clínico do tra- balhador. Com isso iden tificam-se os ri s cos por categoria funcional dos trabalhadores portuários, levando em consideração que a mesma função, em setores diferen tes, pode ter riscos e exigências físicas ou psíquicas diferen tes.

\section{Ações terciárias de saúde}

São as ações dirigidas à reabilitação de seqü elas resultan tes de doenças ou lesões relacion adas ou não ao trabalho.

\section{Inspeções do SESSTP nos locais de trabalho}

Visa manterem bem informados em presa e trabalhador sobre as condições do ambi en te de trabalho, para perceber quaisquer modificações prejudiciais à saúde do trabalhador ou seu de s em penho profissional.

\section{Elaboração de um relatório anual}

Es te virá discriminar, por setores (divisões, secções) da empresa, o número e a natureza dos exames realizados, inclusive exames complementares, estatísticas de resultados anormais, bem como o planejamento para o ano seguinte.

Para um melhor con trole de atos inseguros seria interessante discutir uma nova metodologia educativa para valorizar e esti mular o uso dos EPIs. Is to poderia ser fei to através de aulas expositivas, exibição de vídeos, imagens, fotos, depoimen tos de profissionais de saúde, testemunhos de pessoas vítimas de aciden tes de trabalho e apres entações teatrais. Além disso, deve-se incen tivar e aumentar a participação ativa dos trabalhadores, que poderiam tra zer críticas e su gestões para a mel horia das condições de trabalho.

Em adição às atividades educativas de prevenção de acidentes, poderiam ser criados painéis periódicos, on de seriam abord ados temas que melh orariam aqualidade de vida, reduzindo, significativamente, o índice das doenças sociais. Como sugestão de painéis, poderíamos citar:

\section{- DST/AIDS}

- Diabetes

- Hipertensão

- Drogas

- Higi ene pessoal e do lar

- Alimentação saudável

- Oficinas de arte

- La zer e cultura 
- E ducação física

- Relaxamento

- Ensino para adultos

- Planejamento familiar

- Relações familiares

Os ges tores portuários também poderiam s er convidados a participar dessas atividades a fim de que eles se interem da verd adeira realidade do porto e possam, assim, ges tores e trabalhadores do porto, buscar outras soluções para melhorar a tão de sgastada relação patrãoem pregado.

Con forme Gomes et al. (2003) para a viabilização de tais projetos, poder-se-ia criar uma estratégia para arrecadar recursos com em presas que atuam den tro do porto. O plano estratégi co deve enaltecer a relação custo-ben efício a médio e a longo prazo, principalmen te no que diz respeito à melhoria da qualidade do a ten dimen to aos navios atrac ados; ao aumen to do interesse dos proprietários de embarcações em fazer uso do Porto do Mucuripe; à diminu ição do número de trabalhadores a serem indenizados por aciden tes de trabalho ou causas trabalhistas; à melhoria das relações interpes- soais dos trabalhadores em geral. Con seqüentemente, h averia um aumen to nas arrec ad a çõ e s e lucros para o porto, pa ra as empresas que detêm a exploração do porto e para os trabalhadores.

\section{Conclusão}

A análise dos dados evi dencia que os principais problemas de saúde ineren tes à profissão de estivador são, en tre outros, os distúrbios osteoarticulares e metabólicos (diabetes e hipertensão). Estes se devem não só ao trabalho, mas também e, com gran de influência, ao con tex to de vida destes profissionais. As situações identificadas estão de acordo com as informações da literatura. Neste sentido, a medicina do trabalho atua não somente com ações de prevenção e de tratamento, mas também, de educação. Há, portanto, a necessidade de uma maior liberdade de atuação do profissional médico e de uma maior cooperação dos outros setores do porto a fim de legi timar as medidas que visam con trolar atos inseguros.

\section{Colaboradores}

FFG Caval can teparti c i pou de todas as etapas da el a boração do arti go. ACN Gomes e FRA Noguei ra participaram da elaboração e aplicação dos questionários, análise do s dados, desenvo lvimen to e correção do arti go e atualização das referências bibliográficas. JLM Farias, JMR Pinheiro, EV Albuquerque, ALP Farias, GB Cabral e FAC Magalhães participaram da elaboração e aplicação dos questionários, análise dos dados e des envolvimento do a rti go. M Gom i de ori en tou qua n to à el a boração e aplicação dos questionários e correção do artigo.

\section{Agradecimentos}

Os autores apres entam seus agradecimentos às pessoas que deram inestimáveis con tribuições ao de senvo lvi mento deste artigo, entre as quais se inclu em o dr. Antônio Enéas Vieira (médico do trabalho do OGMO), Josimar (técnico de segurança), Rom eo (engen hei ro de segurança), Ma rcon des (fiscal do OGMO), Mário Jorge (coordenador de gestão portuária da Companhia Docas do Ce ará) e José Sales (membro do Sindicato dos Estivadores). Os autores agradecem, em particular, aos estivadores do Porto Organizado de Fortaleza, que se submeteram à aplicação do instrumen to de s envo lvi do. 


\section{Referências bibliográficas}

Barreiros D 1990. Saú de e segurança nas pequ enas empresas. Revista Brasileira de Saúde Ocupacional 70 (18):25-28.

Brasil. 1993. Lei no 8.630, de 25 de feverei rode 1993. Di spõe sobre o regime jurídico da exploração dos portos organizados e das instituições portuárias e das outras providências. Diá rio Oficial da União, DF, pp. 2351.

Companhia Docas do Ceará. Disponível em $<$ http://www. docasdoceara.com.br>. Acesso em 16 fev 2003.

Convenção Coletiva de Trabalho. Disponível em < http:// 209.161.96.174/fenop/cct/cc_ce1_1.html >. Acesso em 16 de fev 2003.

Gomes ACN et al. 2003. A importância da medicina do trabalho na melhoria da qualidade de vida dos estivadores do Porto do Mucuripe em Fortaleza, Ceará, pp. 447. VII Congresso Brasilei ro de Saúde Coletiva, vol. VIII. Brasília.

Hildebrandt VH 1995. Back pain in the working population: prevalence rates in Dutch trades and professions. Ergonomics 38(6):1283-1298.

Mendes R 1997. Patologia do trabalho. Ed. Atheneu, Rio de Jan eiro.

Merino EAD 1996. Efeitos agudose crônicos causados pelo manu seio e movimentação de cargas no trabalhador. Dis s ertação de mestrado. Faculdade de Engen h a ria de Produção, Un ivers i d ade Federal de Santa Catarina.
Ministério da Saúde do Brasil. 2001. Doenças relacionadas ao tra balho: manual de pro cedimen tos para os serviços de saúde. Brasília. Editora MS.

Na jar HCF \& Morrone LC 1985. Con tribuição à prevenção de acidentes do trabalho na faixa portuária. São Paulo Medical Journal 103(4):203-10.

NR 29 - No rma Regulamentadora de Seg u rança e Saúde no Tra balho Portuário.

OGMO/FOR (Órgão de Gestão de Mão-de - Obra do Trabalho Portuário do Porto Organizado de Fortaleza. Disponível em <http://www.ogmo-ce.com.br $>$. Acesso em 16 fev 2003.

Silva HMS, Musa HM, Costa SC \& Pret to LG 1996. Es stu do retro s pectivo dos ac i den tes de trabalho com associados ao Sindicato dos Arrumadores do Porto de Rio Grande, no perí odo de 1986 a 1995. Revista da As sociação Médica do Rio Grande do Sul 40(4):251-255.

Waskiewicz J 1997. State of the circulatory system in s tevedores. Bulletin of the Institute of Maritime and Tropical Medicine in Gdynia48(1-4):31-40.

Waski ewicz J \& Za borski L 1998. State of circulatory system in equipment opera tors working in harbour. Bulletin of the Institute of Maritime and Tropical Medicine in Gdynia 49(1-4):87-96.

Artigo apresen t ado em 19/10/2004

Aprovado em 12/01/2005

Versão final apresen tada em 18/04/2005 